\title{
WAVEGUIDE-FED SLOT ANTENNAS AND ARRAYS: A REVIEW
}

Sembiam R. Rengarajan

Department of Electrical and Computer Engineering

Calitornia State University

Northridge, CA 91330-8346

Lars G. Josefsson

Ericsson Microwave Systems

S 43184 Mölndal, Sweden

Robert S. Elliott

Department of Electrical Engineering

University of California

Los Angeles, CA 90024

\begin{abstract}
Conceived in the forties, slot array antennas have reached a state of maturity. However, there are still many problems addressed in the current literature. This paper presents an overview of the significant publications on waveguide-fed slot antennas and arrays.
\end{abstract}

\section{EARLY WORK}

The use of slots cut in rectangular waveguides as radiating elements had its beginning during World War II in Canada due to the pioneering work of Watson, Stevenson, and Booker. Stevenson [1] gave a sound theoretical basis to the experimental work of Watson [2] by formulating an integral equation for the slot aperture electric field. The integral equation was solved for resonant-length slots using the waveguide Green's functions and the concept of equivalence of slots and dipoles derived by Booker [3] based on Babinet's principle. Subsequently Oliner [4] developed a variational solution to the slot aperture electric field and deduced the slot characteristics away from the resonant frequency. Oliner's formulation did not take into account the dependence of the resonant length of the slot on

Received 25 November 1997; accepted 10 December 1997. 
its position and orientation in the waveguide wall. Yee [5] extended Oliner's variational procedure and obtained the resonant length of a longitudinal broadwall slot as a function of the slot offset from the centerline.

The slot antenna became popular since the feed and the radiating structure were integrated in the same waveguide. Also, the insertion loss of such a system is very small. Since the excitation of a radiating slot could be controlled precisely by its physical parameters, an array of slots cut in a waveguide wall could be designed to have the desired radiation pattern. Stegen [6] obtained a set of carefully measured data and facilitated the design of slot arrays by producing universal curves for the conductance and susceptance of longitudinal slots cut in the broadwall of a rectangular waveguide as a function of slot length normalized to its resonant length. Stegen's data served as a standard for a long time until the development of accurate computer codes became possible in recent times.

\section{ARRAY DESIGN AND SLOT MODELS}

The method of designing slot arrays evolved since the fifties and eventually an accurate procedure for longitudinal broadwall slots was introduced by Elliott and Kurtz [7] for resonant or standing-wave-type arrays. A resonant array is characterized by a short circuit termination and a half guide wavelength spacing between slots. In that procedure, external mutual coupling between slots was taken into account based on an analogy to dipoles. The design procedure was improved with the assumption of a half-cosine equi-phase aperture distribution that is also valid for slots cut in dielectric filled waveguides [8]. Reciprocity consideration was invoked to determine mutual coupling expressions. The design of traveling wave arrays where the slot spacing is chosen for producing a squinted beam follows the procedure given in [9]. The input data for the above-mentioned design procedures are the self-admittance and the resonant length of slots as a function of offset and length. During the sixties and seventies such data were obtained experimentally. A design procedure using network models for the array and feed has been described by Mazzarella and Panariello [10].

Because of the cost and complexity of the experimental measurement of slot data, there was a need to characterize slots accurately by a computational process. This led to the investigation of the moment method 
solution of the pertinent integral equation for the slot aperture electric field. Khac and Carson used the moment method technique to study the longitudinal slot [11-14]. While their computed values of slot conductance were found to be accurate, the accuracy of computing the resonant length was not adequate due to the use of pulse expansion functions. Pulse functions produce a discontinuous aperture distribution with non-zero values at the slot edges. Further efforts that are reported include a global sinusoidal Galerkin technique $[15,16]$. This method has the advantage that the first expansion term is a very good approximation to the aperture distribution of a resonant slot. Therefore, as few as three terms are adequate for a good solution in many cases. Also, since the expansion functions are smooth and approach zero at the ends they yield good accuracy for the resonant length. However, in order to obtain better than $0.5 \%$ accuracy for the resonant length, one may need about nine expansion functions. Sangster and McCormick [17] demonstrated the use of a design process employing theoretically calculated slot data.

Stern and Elliott's investigation [18] yielded several interesting results. They showed that the global sinusoidal Galerkin and piece-wise sinusoidal Galerkin models were in excellent agreement. Their results for the zerothickness case agreed very well with experimentally measured data for very thin wall slots. For small values of the waveguide 'b' dimension and for large values of slot offset from the centerline, they found that the shunt model was poor. This is due to the fact that the aperture field has a substantial odd-symmetric term with respect to the center. Since modern slot arrays employ reduced height waveguides the previous design procedure has a limitation for such arrays. Therefore Gulick and Elliott proposed a new design procedure [19]. The procedure involved an iterative solution of the coupled integral equations of the entire array using the moment method. This solution has been considered to be limited to small arrays because of the computational burden.

\subsection{Various Radiating Elements}

Moment method solutions of the pertinent integral equations for various slots have been studied because of their applications in arrays. The broadwall compound slot, offset from the centerline and tilted with respect to the waveguide axis, exhibits the interesting property that its amplitude and phase can be independently controlled by offset and tilt, still keeping the slot resonant [20]. Compound slots are ideally suited to traveling wave applications such as fuze antennas of missiles, where one wants to produce 
a beam at an angle with respect to the axis of the missile. In resonant arrays there is a limitation to the amount of phase control. A theoretical investigation of the compound slot has made it possible to understand its properties [21,22]. The singular part of the Green's functions required special treatment in that analysis. The source region singularity, responsible for the $\mathrm{TM}_{00}$ mode contribution in the moment method analysis, has been noted previously [13]. For narrow slots the edge condition is found to be not significant and an assumption of a uniform transverse distribution yields very accurate results. The wall thickness effect may be taken into account rigorously by treating the thick aperture as a cavity [21] or as a stub waveguide [16]. The centered inclined radiating slot is another useful antenna element that behaves as an excellent series element [23]. Numerical difficulties encountered in the study of the transverse slot with the use of pulse expansion and point matching procedure have been circumvented by a choice of edge based expansion functions [24].

Josefsson [25] has presented a solution to the transverse slot radiating into a half-space region or into a region of parallel plates. The use of baffles in the exterior region allows one to have a slot spacing of one guide wavelength and suppress the grating lobes. One major problem of this radiating element is that there is not enough control of excitation amplitude, and hence, the input impedance of such an array is very high, resulting in a matching problem. Recently Dich and Rengarajan [26] analyzed the transverse slot radiating into a finite-length parallel plate region opening into a half-space. The effects of finite width parallel plates are illustrated by the experimental results provided in that work. The problem of the longitudinal slot cut in the broadwall of a dielectric-filled rectangular waveguide is addressed in [27]. Joubert and McNamara investigated the dyadic Green's functions for a partly dielectric-loaded rectangular waveguide [28] and have analyzed the longitudinal slot cut in such a waveguide [29]. The transverse slot cut in a partly dielectric-loaded waveguide provides greater control of excitation and it is possible to have less than one free-space wavelength spacing between slots, still keeping the slot spacing equal to one guide-wavelength [30].

Rexberg [31] and Katehi [32] have determined the properties of a longitudinal slot with a dielectric cover. This subject had previously been studied by Bailey $[33,34]$. Falk [35, 36] presented the solution to the longitudinal slot cut in the broad wall of a single ridge waveguide. A moment method solution of the problem of a longitudinal slot radiating 
between infinite parallel plate waveguides was presented by Forooraghi [37]. The problem of finite-length parallel plate waveguides has been solved in terms of a spectrum of two-dimensional solutions using the Fourier transform technique [38, 39]. In a further development [40] the spectral domain technique has been applied to a longitudinal slot radiating into an arbitrary cylindrical outer structure. The use of baffles reduces the off-axis lobes (butterfly lobes) produced by alternating slot offsets in a conventional slot array, first analyzed by Gruenberg [41] and later studied by Kurtz and Yee [42]. Baffle-like structures are also used in some dualpolarized slot arrays [43]. Centered longitudinal slots excited by means of posts [44] or irises eliminate Gruenberg lobes. The use of probes was discussed first by Clapp [45]. Iris-excited slots have been addressed in [4648]. It has been found that a centered longitudinal slot excited by a compound iris exhibits broader bandwidth than an offset slot since the resonant characteristics of the slot and the compound iris are complementary $[46,48]$. Parallel plate radial line slotted arrays were investigated by Kelly and Goebels $[49,50]$. Later similar antennas were studied extensively by Ando and others, e.g., [51]. A waveguide-fed parallel plate array antenna has been investigated by Hirokawa et al. [52].

The narrow wall tilted slot usually extends to a small region on both broadwalls. The complexity of the exterior region for this problem makes it very difficult to analyze. Compact resonant structures that do not extend into the broad wall, such as I- or C-shaped elements, have been investigated in the past [53-55]. The narrow-wall slot has been analyzed by employing approximate exterior Green's functions by Pan et al. [56, 57]. Numerical techniques such as the finite-difference time domain technique and the finite element technique may be employed to obtain slot data necessary for design or analysis [58,59]. An array of tilted narrow wall slots gives rise to cross polarization in the off-axis planes. Ajioka proposed a solution to avoid the cross polarization problem by keeping the slots untilted. In order to excite the slots, two wires were used inside the waveguide for each slot. This problem, as well as a variation involving etched strips in a dielectric instead of wires, have been studied recently [60-62]. Dudley [63] investigated iris excited narrow wall slots.

\subsection{Extension/Variation of the Design Procedure}

The design of an array of centered-inclined broadwall slots, by modeling them as series impedances in a transmission line, is discussed in [64]. The mutual coupling effects were found to be less in that case than those for 
longitudinal slots. Kim and Elliott [65] studied the problem of a longitudinal slot array fed by single-ridge waveguide. Hamadallah [66] modified Elliott's design equations to allow the analysis of a slot array. These equations may be used to study the performance of an array at various frequencies in the desired band. A variation of a traveling wave array with a center feed has one half of the array in the 'forward-fire' mode and the other half in the 'backward-fire' mode. The two halves produce beams pointing in the same direction. Such a pattern is found to be more stable as a function of frequency as compared to a typical end-fed traveling wave array [67-69]. The design of a planar array as an extension of the procedure for linear arrays is presented by Elliott [70]. The concept of incremental conductance, first introduced by Watson [2], may be used to design any reasonably large slot array by following the procedure given in [70]. Yee [7I] has compared the mutual coupling effects for an infinite array and that for a finite array and found the infinite array model to be a good starting approximation in many cases. Derneryd and Petersson [72] studied the overloading effects of the radiating slots on bandwidth. Overloading was found to improve the impedance bandwidth whereas it reduces the bandwidth for the radiation pattern performance. Therefore, an optimum normalized total active admittance of about two for each radiating waveguide is recommended. The design of a shaped beam pattern produced by a planar array of longitudinal slots with compound coupling slots has been presented [73]. As the number of elements in an array gets larger the bandwidth becomes lower due to the resonant nature of the array. In order to realize greater bandwidth, the array is broken into subarrays. Watson and Ringer [74] discuss some practical considerations in the design of feeding networks.

\subsection{Analysis and Computation of External Mutual Coupling}

Mutual coupling requires most of the computation time in the analysis or synthesis of slot arrays. Therefore, the analysis and computation of mutual coupling has received much attention in the literature since the early fifties [75]. The dipole analogy to slots has been exploited in the computation by Hansen and Brunner [76]. A Taylor series approximation around half wavelength slots is employed by Mazzarella and Panariello [77]. The geometrical theory of diffraction has been used to include the edge effects of a finite ground plane $[78,79]$. Series expressions have also been investigated [80]. The mutual coupling between conventional and compound slots is studied in [81] wherein the computation of the mutual coupling expression for narrow slots has been reduced to a single integral. 
Pan et al. [82] have presented results for mutual coupling between sidewall slots. Their method is approximate since the mutual interaction between corners is not accounted for. Rengarajan [83] has investigated the mutual coupling between longitudinal broadwall slots radiating between baffles. A similar analysis for transverse slots has been published recently [84]. Mutual coupling between slots radiating into different exterior cylindrical structures has been investigated by different formulations such as the electric field integral equation (EFIE) and the magnetic field integral equation (MFIE) for the axial fields and MFIE for the tangential components [85].

A planar array employed in mono-pulse applications produces three simultaneous beams, one sum pattern and two difference patterns. Since the same aperture is used for all three beams with different feed networks, each slot experiences different mutual coupling effects for each of the three beams. Strictly, the design procedure will yield three different values of offset and length for the three beams. Clearly, it is not possible to realize the slots in a single aperture. Schaffner et al. [86] provide an optimum compromise by averaging the three values of offsets and lengths one gets for each slot. The same problem exists for waveguide slotted arrays with electronically scanned beams. Derneryd provides a good compromise for the aperture distribution of mono-pulse patterns [87].

\subsection{Coupling Slots}

Planar slot arrays generally consist of a main waveguide and a family of orthogonal branch waveguides containing radiating slots. In the case of longitudinal broadwall slot arrays, coupling slots cut in the common broadwall feed desired amounts of power into each branch waveguide. Elliott and Kurtz [88] developed the key relations for the four-port couplers. Integral equation/moment method solutions indicate that the centered-inclined coupling slot possesses desirable characteristics [89] whereas longitudinal/transverse coupling slots may have some problems [90]. The compound coupling slots have the property that generally it is possible to realize any amplitude and phase for coupling, still keeping the slots resonant [91]. For narrow wall slot arrays a coupling slot configuration has been proposed by Hilburn et al. [92]. Broadwall slot coupling into butt-ended waveguides, analyzed by Rengarajan and Elliott [93] may have applications as experimental fixtures or feeds. Centeredinclined coupling slots have also been analyzed by Hanyang and Wei [94]. 


\subsection{Weakly Excited Slots, Wide Slots and Round-Ended Slots}

When the number of radiating or coupling slots becomes large in a waveguide, the amount of coupling from each slot becomes small. A weakly excited broadwall slot is characterized by a small amount of offset and/or tilt. In that case the conventional assumptions employed in the analysis such as ignoring E-longitudinal and the use of even transverse distribution for the E-transverse are inadequate. Therefore, the conventional moment method model becomes poor and it fails completely for a centered longitudinal slot. Rengarajan and Derneryd [95] proposed an improved scattering model that corrects the moment method data with experimental data for centered slots. Peterson and Rengarajan [96] have given a rigorous solution of the weak slot problem by solving for both components of the slot aperture electric field. The complete aperture distribution is obtained in terms of global polynomial basis functions, Jacobi and Legendre functions with appropriate edge conditions. They have shown that the E-longitudinal has a significant contribution to the scattered field. A simple prescription for the weak slot problem in terms of parasitic effects at the slot edges has been proposed by Albertsen [97].

Sangster and McCormick [98] have investigated the wide slot problem without any special consideration to the longitudinal component of the Efield. Lodone [99] has shown that the longitudinal component of the electric field is significant for slots with a length to width ratio less than seven. Peterson-Espino et al. [100] have demonstrated excellent agreement between results computed by the rigorous model [96] and experimental results for very wide slots. The analysis of a slot generally assumes a square end because of the mathematical convenience whereas slots made by a milling process have semi-circular ends. Theoretical treatment of round-ended slots has not been successful so far [101]. Previous work has shown that equivalence between round-ended slots and square-ended slots based on an 'equal area criterion' is generally a satisfactory engineering solution $[16,95]$.

\section{ADVANCEMENTS IN THE ANALYSIS}

Demanding performance requirements of modern array antennas have given rise to advancements in the analyses of slot arrays. Elliott and O'Loughlin [102] found that the $\mathrm{TE}_{20}$ mode coupling between adjacent radiating longitudinal slots was significant when the slots were close to the 
centerline. When three different waveguide heights were studied for the same antenna, the smallest offsets occurred for quarter-height guides in their study. Later studies $[103,104]$ showed that the $T E_{20}$ coupling was the most significant of the higher-order modes and that it is significant for small values of offsets and tilts. In the case of a junction involving a coupling slot and a pair of straddling radiating slots, higher-order mode coupling effects are found to be significant. Analysis of such a junction problem is facilitated by the Green's functions with a spectral integral representation as presented by Mahon [105], since the source region and field regions are easily separable even for a tilted slot. Rengarajan and Shaw [106] have solved the junction problem, with the use of Mahon's Green's functions when a singularity was encountered in the coupling problem. Seki's virtual cavity technique $[107,108]$ obviates the need to work with the singularity in the Green's function by a different formulation. It has been successfully employed in [61, 62]. Senior [109] has presented results for the higher-order mode coupling effects for the shunt-series coupling junction. Higher-order mode coupling effects are less serious for this junction compared to the conventional junctions employing centered-inclined coupling slots.

Petersson et al. $[110,111]$ have presented the results of the ERS -1 slot array antenna design and performance analysis. Design of slot arrays pose challenges when severe mutual coupling effects are present. One needs to investigate alternate slot excitations producing the same given power pattern. In some cases it is possible to realize a beam with a small squint that is compensated for mechanically. The multiport approach to design a planar array of narrow wall slots, implemented in the Canadian Radarsat antenna, is described by Wood [112]. The radar cross-section (RCS) of the slot array has not received much attention in the literature. Josefsson [113] has studied the problem of scattering from a single slot. Fan and Jin [114, 115] have presented analytical results for the RCS of cylindrical and planar slot arrays in terms of two contributions, structural scattering and slot scattering. Sangster et al. [116, 117] have discussed waveguide-fed dual polarization systems. Dual polarization slot antennas are also realized by stacking waveguides with alternating vertical and horizontal polarization. Longitudinal and transverse broadwall slots and narrow wall slots have been employed in such applications [43]. Ando and Hirokawa have given an excellent overview of radial line and conventional parallel plate fed slot arrays for direct broadcast satellite and millimeter wave applications [51]. 


\section{MANUFACTURING TECHNIQUES}

Standard numerically controlled metal machining and metal joining processes such as dip-brazing, soldering, and electron beam welding have successfully been used in the manufacturing of waveguide slotted array antennas. However, high precision is required due to narrow tolerances for advanced applications. Laser cutting and laser welding have also been used, especially with small values of wall thickness. Planar slotted arrays for the $60 \mathrm{GHz}$ band have been realized using photo-lithography techniques [118]. An overview of manufacturing methods is presented by Sikora and Womack [119]. Where light-weight and thermally stable structures are desired metallized composite materials have found use [120, $121]$.

\section{SLOT ARRAY ANTENNA SYSTEMS}

Waveguide slot array antennas have found wide-spread use, both for communication antennas and for radar applications. For lack of space only a few significant examples are referenced here. An advanced flat plate array with several sub-apertures has been described by Cross et al. [122]. A 10-meter long fixed beam C-band array is used in a space-borne SAR application (ERS-1) [110]. The waveguide slot array is ideally suited for one-dimensional electronic scanning. An early implementation using frequency scan is found in the AN/SPS-48 radar and similar ones described in [123]. Electronic scanning of slotted waveguide arrays by means of electronic phase shifters is employed in the well-known AWACS airborne radar [124] and the Firefinder AN/TPQ-36 radar [125], both with edge slots in the narrow wall. Antenna systems with the slots in the broad wall of ridge loaded waveguides have been employed in several cases, e.g., the ARTHUR and Joint Stars projects [126-128]. In the latter the broad wall centered longitudinal slot is excited by alternating the height of the ridges. Scanned array systems using solid state transmit/receive module technology in combination with waveguide slot arrays have also been developed $[129,130]$.

\section{CONCLUSION}

Slot antennas and arrays have been investigated extensively in the literature. Theoretical solutions are available for a number of elements, 
arrays, and coupling mechanisms. These antennas enjoy numerous applications since it is possible to design them precisely for the required performance and they offer low losses. Although there is a wealth of literature on waveguide-fed slot antennas and arrays, we could not include many excellent papers in the list of references because of the restriction on the size of this paper.

\section{REFERENCES}

[1] A. F. Stevenson, "Theory of slots in rectangular waveguides," Journal of Applied Physics, vol. 19, pp. 24-38, 1948.

[2] W. H. Watson, The Physical Principles of Waveguide Transmission and Antenna Systems, Clarendon Press, Oxford, 1947.

[3] H. G. Booker, "Slot aerials and their relations to complementary wire aerials (Bahinet's Principle)," JIEE (London), 93, pt. III A: pp. 620-626, 1946.

[4] A. A. Oliner, "The impedance properties of narrow radiating slots in the broad face of rectangular waveguide," IRE Trans. Antennas Propagat., vol. AP-5, no. 1, pp. 4-20, Jan. 1957.

[5] H. Y. Yee, "Impedance of narrow longitudinal shunt slot in a slotted waveguide array," IEEE Trans. Antennas Propagat., vol. AP-22, no. 4, pp. 589-592, July 1974.

[6] R. J. Stegen, "Longitudinal Shunt Slot Characteristics," Technical Report 261, Hughes Technical Memorandum, Nov. 1971. (Stegen's data are reproduced in R. C. Johnson and H. Jasik, Antenna Engineering Handbook, McGraw Hill, New York, 1984.)

[7] R. S. Elliott and L. A. Kurtz, "The design of small slot arrays," IEEE Trans. Antennas Propagat., vol. AP-26, no. 2, pp. 214-219, Mar. 1978.

[8] R. S. Elliott, "An improved design procedure for small arrays of shunt slots," IEEE Trans. Antennas Propagat., vol. AP-31, no. 1, pp. 48-53, Jan. 1983.

[9] R. S. Elliott, "On the design of traveling-wave-fed longitudinal shunt slot arrays," IEEE Trans. Antennas Propagat., vol. AP-27, no. 5, pp. 717-720, Sept. 1979.

[10] G. Mazzarella and G. Panariello, "Design of slot arrays for SAR applications", Alta Frequenza, vol. LV, no. 6, pp 359-364, Nov.Dec. 1986, incl. Addenda, vol. LVII, no. 2, ppl 57-158, Feb.-Mar. 1988.

[11] T. V. Khac and C. T. Carson, "Coupling by slots in rectangular 
waveguides with arbitrary wall thickness," Electronics Letters, vol. 8, pp. 296-297, 1972.

[12] T. V. Khac and C. T. Carson, "Impedance properties of a longitudinal slot antenna in the broad face of a rectangular waveguide" IEEE Trans. Antennas Propagat., vol. AP-21, no. 5, pp. 708-710, Sept. 1973.

[13] T. V. Khac and C. T. Carson, "The TM ${ }_{00}$ mode and rectangular waveguide slot discontinuities" Electronics Letters, vol. 9, pp. 431432, 1973.

[14] T. V. Khac, "A study of some slot discontinuities in rectangular waveguides," Ph.D. dissertation, Monash University, Australia, 1974.

[15] R. W. Lyon and A. J. Sangster, "Efficient moment method analysis of radiating slot in a thick-walled rectangular waveguide," Proc. IEE, 128, no. 4, pp. 197-204, Aug. 1981.

[16] L. G. Josefsson, "Analysis of longitudinal slots in rectangular waveguides,” IEEE Trans. Antennas Propagat., vol. 35, no. 12, pp. 1351-1357, Dec. 1987.

[17] A. J. Sangster and A. H. I. McCormick, "Theoretical design/synthesis of slotted waveguide arrays," Proc. IEE, 136, pt. H, pp. 39-46, 1989.

[18] G. J. Stern and R. S. Elliott, "Resonant length of longitudinal slots and validity of circuit representation: theory and experiment," IEEE Trans. Antennas Propagat., vol. 33, no. 11, pp. 1264-1271, Nov. 1985.

[19] J. J. Gulick and R. S. Elliott, "The design of linear and planar arrays of waveguide-fed longitudinal slots," Electromagnetics, vol. 10, pp. 327-347, 1990.

[20] B. J. Maxum, "Resonant slots with independent control of amplitude and phase," IRE Trans. Antennas Propagat., vol. AP-8, no. 4, pp. 383-388, Jul. 1960.

[21] S. R. Rengarajan, "Compound radiating slots in a broad wall of a rectangular waveguide," IEEE Trans. Antennas Propagat., vol. 37, no. 9, pp. 1116-1123, Sept. 1989.

[22] S. R. Rengarajan, "Compound broadwall slots for array applications," IEEE Antennas and Propagation Magazine, vol. 32, no. 6, pp. 19-26, Dec. 1990.

[23] S. R. Rengarajan, "Scattering characteristics of a centred-inclined slot in a broad wall of a rectangular waveguide," IEE Proc. vol. 137, pt. H, no. 6, pp. 343-348, Dec. 1990.

[24] P. K. Park, G. J. Stern, and R. S. Elliott, "An improved technique 
for the evaluation of transverse slot discontinuities in rectangular waveguide," IEEE Trans. Antennas Propagat., vol. AP-31, no. 1, pp. 148-154, Jan. 1983.

[25] L. G. Josefsson, "A waveguide transverse slot for array application," IEEE Trans. Antennas Propagat., vol. 41, no. 7, pp. 845-850, July 1993.

[26] M. Dich and S. R. Rengarajan, "The self impedance of a waveguidefed transverse slot radiating between baffles," Special Issue on Slot Antennas and Arrays, Electromagnetics, vol. 18, 1998 (this issue).

[27] S. R. Rengarajan and M. Steinbeck, "Longitudinal slots in dielectric-filled rectangular waveguides," Microwave and Optical Technology Letters, vol. 6, no. 11, pp. 649-652, Sep. 5, 1993.

[28] J. Joubert and D. A. McNamara, "Dyadic Green's function of electric type for inhomogeneously loaded rectangular waveguides," IEE Proc., pt. H, Microwaves Antennas, and Propagation, vol. 136, no. 6, pp. 469-474, Dec. 1989.

[29] J. Joubert and D. A. McNamara, "Analysis of radiating slots in a rectangular waveguides inhomogeneously loaded with a dielectric slab," IEEE Trans. Antennas Propagat., vol. 41, no. 9, pp. 12121221 , Sep. 1993.

[30] J. Joubert, "A transverse slot in the broad wall of inhomogeneously loaded rectangular waveguides for array application," IEEE Microwave and Guided Wave Letters, vol. 5, no. 2, pp. 37-39, Feb. 1995.

[31] L. Rexberg, "Vector Fourier transform analysis of dielectric-covered slots in the broad wall of a waveguide", Microwave Opt. Technol. Lett., vol. 2, pp. 360-363, 1988.

[32] P. B. Katehi, "Dielectric-covered waveguide longitudinal slots with finite wall thickness," IEEE Trans. Antennas Propagat., vol. 38, no. 7, pp. 1039-1045, July 1990.

[33] M. Bailey, "Design of dielectric-covered resonant slots in a rectangular waveguide," IEEE Trans. Antennas Propagat., vol. 15, no. 5, pp. 594-598, Sept. 1967.

[34] M. Bailey, "The impedance properties of dielectric-covered narrow radiating slots in the broad face of a rectangular waveguide," IEEE Trans. Antennas Propagat., vol. 18, no. 5, pp. 596-603, Sept. 1970.

[35] K. Falk, "Conductance of a longitudinal resonant slot in a ridge waveguide," IEE Proc., vol. 134, pt. H, pp. 98-100, Feb. 1987.

[36] K. Falk, "Admittance of a longitudinal resonant slot in a ridge waveguide," IEE Proc., vol. 135, pt. H, pp. 263-268, Aug. 1988.

[37] K. Forooraghi, "Analysis of self-admittance of a longitudinal shunt 
slot radiating into a parallel plate region," Microwave and Optical Technology Letters, vol. 1, no. 8, pp. 305-308, Oct. 1988.

[38] K. Forooraghi, P.-S. Kildal, and S. R. Rengarajan, "Admittance of an isolated waveguide-fed slot radiating between baffles using a spectrum of two-dimensional solutions," IEEE Trans. Antennas Propagat., vol. 41, no. 4, pp. 422-428, Apr. 1993.

[39] P.-S. Kildal, S. R. Rengarajan, and A. Moldsvor, "Analysis of nearly cylindrical antennas and scattering problems using a spectrum of two-dimensional solutions," IEEE Trans. Antennas Propagat, vol. 44, no. 8, pp. 1183-1192, Aug. 1996.

[40] J. Wettergren and P.-S. Kildal, "Admittance of a longitudinal waveguide slot radiating into an arbitrary cylindrical structure," IEEE Trans. Antennas Propagat., vol. 43, no. 7, pp. 667-673, July 1995.

[41] H. Gruenberg, "Second order beams of slotted waveguide arrays," Canadian Journal of Physics, vol. 31, pp 55-69, 1953.

[42] L. A. Kurtz and J. S. Yee, "Second order beams of two dimensional slot arrays," IRE Trans. Antennas Propagat., vol. 5, no. 4, pp. $356-$ 362, Oct. 1957.

[43] L. Josefsson, "A dual polarised slotted waveguide array antenna," URSI Electromagnetic Theory Symp., Sydney, Australia, Aug. 17$20,1992$.

[44] H. S. Jones and W. G. Heinard, "An improved slot array using post excitation," Microwave Journal, vol. 8, pp 69-72, July 1965.

[45] R. E. Clapp, "Probe-fed slots as radiating elements in linear arrays," MIT Rad. Lab. Series Report no. 455, 25 Jan. 1944.

[46] R. Tang, "A slot with variable coupling and its application to a linear array," IRE Trans. Antennas Propagat., vol. AP-8, no. 1, pp. 97-101, Jan. 1960.

[47] W. E. Kummer, "Iris-excited shunt slots in rectangular waveguide, theory and experiment," Ph.D. dissertation, University of Califomia Los Angeles, 1989.

[48] I. Nystrom, "Iris-excited centered slots," MS thesis, Chalmers University of Technology, Gothenburg, Sweden, I990-91.

[49] F. J. Goebels and K. C. Kelly, "Arbitrary polarization from annular slot planar antennas," IRE Trans. Antennas Propagat., vol. 9, no. 4, pp. 342-349, July 1961.

[50] K. C. Kelly and F. J. Goebels, "Annular slot monopulse antenna arrays," IEEE Trans. Antennas Propagat., vol. 12, no. 4, pp. 391403, July 1964.

[51] M. Ando and J. Hirokawa, "Single layer slotted waveguide arrays 
for DBS reception and millimeter-wave applications," Special Issue on Slot Antennas and Arrays, Electromagnetics, vol. 18, 1998 (this issue).

[52] J. Hirokawa, M. Ando, and N. Goto, "Waveguide-fed parallel plate slot array antenna," IEEE Trans. Antennas Propagat., vol. 40, no. 2, pp. 218-223, Feb. 1992.

[53] R. J. Chignell and J. Roberts, "Compact resonant slot for waveguide arrays," Proc. IEE, vol. 125, no. 11, pp. 1213-1216, Nov. 1978.

[54] H. Y. Yee and P. Stellitano, "I-Slot characteristics," IEEE Trans. Antennas Propagat., vol. 40, no. 2, pp. 224-228, Feb. 1992.

[55] T. Sphicopoulos, "C-slot: a practical solution for phased arrays of radiating slots located on the narrow side of rectangular waveguides," IEE Proc., vol. 129, pt. H, no. 2, pp. 49-55, Apr. 1982.

[56] C.-G. Pan, P. Hsu, and R.-B. Wu, "Moment method analysis of sidewall inclined slots in rectangular waveguides," IEEE Trans. Antennas Propagat., vol. 39, no. 1, pp. 68-73, Jan. 1991.

[57] C.-G. Pan, R.-B. Wu, and P. Hsu, "Variational analysis of inclined slots in the narrow wall of a rectangular waveguide," IEEE Trans. Antennas Propagat., vol. 42, no. 10, pp. 1455-1458, Oct. 1994.

[58] E. A. Kraut, J. C. Olivier, and J. B. West, "FDTD solution of Maxwell's equations for an edge slot penetrating adjacent broadwalls of a finite wall thickness waveguide," IEEE Trans. Antennas Propagat., vol. 42, no. 12, pp. 1646-1648, Dec. 1994.

[59] K. W. Brown, "Design of waveguide slotted arrays using commercially available finite element software," IEEE Antennas and Propagation Symposium Digest, vol. 2, pp. 1000-1003, Baltimore, MD, 1996.

[60] S. Hashemi-Yeganeh and R. S. Elliott, "Analysis of untilted edge slots excited by tilted wires," IEEE Trans. Antennas Propagat., vol. 38, no. 11, pp. 1737-1745, Nov. 1990.

[61] J. Hirokawa and P.-S. Kildal, "Excitation of an untilted narrow-wall slot in a rectangular waveguide by using etched strips on a dielectric plate," IEEE Trans. Antennas Propagat., vol. 45, no. 6, pp. 10321037, June 1997.

[62] J. Hirokawa, L. Manholm, and P.-S. Kildal, “Analysis of an untilted wire-excited slot in the narrow-wall of a rectangular waveguide by including the actual external structure," IEEE Trans. Antennas Propagat., vol. 45, no. 6, pp. 1038-1044, June 1997.

[63] D. G. Dudley, "An iris-excited slot radiator in the narrow wall of rectangular waveguide," IRE Trans. Antennas Propagat., vol. 9, no. 4, pp. 361-364, July 1961 . 
[64] M. Orefice and R. S. Elliott, "Design of waveguide-fed series slot arrays," Proc. IEE, 129, pt. H, no. 4, pp. 165-169, Aug. 1982.

[65] D. Y. Kim and R. S. Elliott, "A design procedure for slot arrays fed by single-ridge waveguide," IEEE Trans. Antennas Propagat., vol. 36, no. 11, pp. 1531-1536, Nov. 1988.

[66] M. Hamadallah, "Frequency limitations on broad band performance of shunt slot arrays," IEEE Trans. Antennas Propagat., vol. 37, no. 7, pp. 817-823, July 1989.

[67] W. R. O'Loughlin, Y. U. Kim, and R. S. Elliott, "Pattern synthesis for a forward-fire/backward-fire linear array," IEEE Trans. Antennas Propagat., vol. 37, no. 6, pp. 721-727, June 1989.

[68] E. L. Holzman and R. S. Elliott, "Design procedure for a forwardfire/backward-fire longitudinal slot array in a rectangular waveguide," Journal of Electromagnetic Waves and Applications, vol. 4 , no. 4 , pp. 809-828, 1990.

[69] L. Josefsson, A. Derneryd, and E. R. Karlsson, "A phase steered slotted waveguide array with non-squinting beam", Military Microwaves '90 Conference, 11-13 July 1990.

[70] R. S. Elliott, "The design of waveguide-fed slot arrays," in Y. T. Lo and S. W. Lee, Antenna Handbook, New York, Van Nostrand Reinhold, 1988.

[71] H. Y. Yee, "The design of large waveguide arrays of shunt slots," IEEE Trans. Antennas Propagat., vol. 40, no. 7, pp. 775-781, July 1992.

[72] A. Derneryd and R. Petersson, "Bandwidth characteristics of monopulse slotted waveguide antennas", Proc. of Fourth Int. Conf. Antennas Propagat., (ICAP-85), pp. 27-30, 1985.

[73] S. R. Rengarajan and A. Derneryd, "Application of compound coupling slots in the design of shaped beam antenna patterns," IEEE Trans. Antennas Propagat,, vol. 41, no. 1, pp. 59-65, Jan. 1993.

[74] C. K. Watson and K. Ringer, "Feed network design for airborne monopulse slot-array antennas," Microwave Journal, vol. 31, pp. 129-145, June 1988.

[75] M. J. Ehrlich and J. Short, "Mutual coupling considerations in linear-slot array design”, Proc. IRE, vol. 42 , no. 6, pp. 956-961, June 1954.

[76] R. C. Hansen and G. Brunner, "Dipole mutual impedance for design of slot arrays,” Microwave Journal, vol. 22, pp. 54-56, Dec. 1979.

[77] G. Mazzarella and G. Panariello, "On the evaluation of mutual coupling between slots," IEEE Trans. Antennas Propagat., vol. 35, no. 11, pp. 1289-1292, Nov. 1987. 
[78] G. Mazzarella and G. Panariello, "Evaluation of edge effects in slot arrays using the geometrical theory of diffraction," IEEE Trans. Antennas Propagat., vol. 37, no. 3, pp. 392-395, Mar. 1989.

[79] L. Josefsson, "Mutual coupling calculations including edge effects," Electronics Letters, vol. 30, no. 25, pp 2087-2088, Dec. 1994.

[80] B. Nauwelaers and A. van de Capelle, "Series expressions for mutual coupling between magnetic currents," in Proc. ICEAA, Torino, Italy, pp. 199-202, Sep. 1989.

[81] S. R. Rengarajan and E. Gabrelian "Efficient and accurate evaluation of external mutual coupling between compound broad wall slots," IEEE Trans. Antennas Propagat., vol. 40, no 6, pp. 733737, June 1992.

[82] C.-G. Pan, P. Hsu, and R.-B. Wu, "Corner effects on mutual impedance between edge slots," IEEE Trans. Antennas Propagat., vol. 41, no. 4, pp. 488-492, Apr. 1993.

[83] S. R. Rengarajan, "Mutual coupling between waveguide-fed longitudinal broad wall slots radiating between baffles," Electromagnetics, vol. 16, no. 6, pp. 671-683, Nov.-Dec., 1996.

[84] M. Dich and S. R. Rengarajan, "Mutual coupling between waveguide-fed transverse broad wall slots radiating between baffles," Electromagnetics, vol. 17, no. 5, pp. 421-436, Sep.-Oct., 1997.

[85] S. R. Rengarajan, "Mutual coupling between slots cut in rectangular cylindrical structures: Spectral domain technique," Radio Science, vol. 31, no. 6, pp. 1651-1661, Nov.-Dec. 1996.

[86] J. H. Schaffner, D. Kim, and R. S. Elliott, "Compromises among optimum sum and difference patterns for planar waveguide-fed slot arrays," Alta Frequenza, vol. 50, pp. 312-319, Nov.-Dec. 1981.

[87] A. G. Derneryd, "Optimization of difference pattern sidelobes in the presence of fictitious blockage," Journal of Electromagnetic Waves and Applications, vol. 2, no. 5/6, pp. 535-543, 1988.

[88] R. S. Elliott and L. A. Kurtz, "Main-line/branch-line couplers for waveguide slot arrays," IEEE Trans. Antennas Propagat., vol. AP27, no. 2, pp. 256-259, Mar. 1979.

[89] S. R. Rengarajan, "Analysis of centered-inclined waveguide slot coupler”, IEEE Trans., vol. 37, no. 5, pp. 884-889, May 1989.

[90] S. R. Rengarajan, "Characteristics of a longitudinal/transverse coupling slot in crossed rectangular waveguides," IEEE Trans., vol. 37, no. 8, pp. 1171-1177, Aug. 1989.

[91] S. R. Rengarajan, "Compound coupling slots for arbitrary excitation of waveguide-fed planar slot arrays," IEEE Trans. Antennas 
Propagat., vol. 38, no. 2, pp. 276-280, Feb. 1990.

[92] J. L. Hilburn, R. A. Kinney, R. W. Emmett, and F. H. Prestwood, "Frequency-scanned X-band waveguide array," IEEE Trans.

Antennas Propagat., vol. AP-20, no. 4, pp. 506-509, July 1972.

[93] S. R. Rengarajan and R. S. Elliott, "Broadwall slot coupling into butt-ended waveguide," Microwave and Optical Technology Letters, vol. 7, no. 10, pp. 460-464, July 1994.

[94] W. Hanyang and W. Wei, "Moment method analysis of a feeding system in a slotted-waveguide antenna," Proc. IEE, vol. 135, pt. H, no. 5, pp. 313-318, Oct. 1988.

[95] S. R. Rengarajan and A. Derneryd, "Improved scattering model for weakly excited compound slots," Microwave and Optical

Technology Letters, vol. 6, pp. 504-507, June 10, 1993.

[96] C. Peterson and S. R. Rengarajan, "Rigorous analysis of weakly excited broadwall slots," Electronics Letters, vol. 30, no. 12, pp. 921-922, June 1994.

[97] N. C. Albertsen, "S-parameters for weakly excited slots," Special Issue on Slot Antennas and Arrays, Electromagnetics, vol. 18, 1998 (this issue).

[98] A. J. Sangster and A. H. I. McCormick, "Resonance characteristics of waveguide slot radiators with moderate width to length ratios," IEE Proc., vol. I35, pt. H, no. 5, pp. 319-322, Oct. 1988.

[99] G. Lodone, "Electromagnetic characterization of slots and their interactions in an array environment," Proc. 17th European Microwave Conference, pp. 561-566, 1987.

[100] C. Peterson-Espino, J. Mahon, and S. Rengarajan, "A rigorous analysis of wide slots," IEEE International Antennas and Propagation Symposium Digest, vol. 3, pp. 1962-1965, Montreal, Canada, July 1997.

[101] A. J. Sangster and A. H. I. McCormick, "Moment method applied to round-ended slots," Proc. IEE, vol. 134, no. 3, pt. H, pp. 310-314, June 1987.

[102] R. S. Elliott and W. R. O'Loughlin, "The design of slot arrays including internal mutual coupling," IEEE Trans. Antennas Propagat., vol. 34, no. 9, pp. 1149-1154, Sept. 1986.

[103] S. R. Rengarajan, "Higher-order mode coupling in feeding waveguide of a planar slot array", IEEE Trans. Microwave Theory Tech., vol. 39, no. 7, pp. 1219-1223, July 1991.

[104] S. R. Rengarajan and D. D. Nardi, "On internal higher order mode coupling in slot arrays," IEEE Trans. Antennas Propagat., vol. 39, no. 5, pp. 694-698, May I991. 
[105] J. Mahon, “An alternative representation for Green's functions used in rectangular waveguide slot analysis," Journal of Electromagnetic Waves and Applications, vol. 4, no. 7, pp. 661-672, 1990.

[106] S. R. Rengarajan and G. M. Shaw, "Accurate Characterization of coupling junctions in waveguide-fed planar slot arrays", IEEE Trans. Microwave Theory Tech., vol. 42, no. 12, pp. 2239-2248, Dec. 1994.

[107] H. Seki, "An alternative representation of electromagnetic fields in a rectangular waveguide with an aperture and its wall", IEICE Natl. Conv. Rec., Japan, vol. 1, p. 16, Sept. 1984 (in Japanese).

[108] H. Seki, "Analysis of waveguide directional filters by the moment method", Int. J. Microwave Millimeter-Wave Computer-Aided Eng., vol. 3, no. 3, pp. 183-191, 1993.

[109] D. C. Senior, "Higher-order mode coupling effects in a shunt-series coupling junction of a planar slot array antenna", Ph.D. dissertation, University of California, Los Angeles, CA, 1986.

[110] R. Petersson, E. Kallas, and K. van't Klooster, "Radiation performance of the ERS-1 SAR EM antenna," IEEE Int. Antennas Propagat. Symp. Digest, pp. 212-215, 1988.

[111] R. Petersson, "Slotted waveguide array with shaped fan beam," IEE Colloquium on Shaped Beam Antennas, London, 1987.

[112] P. J. Wood, "Planar slotted waveguide array design using the multiport technique," Special Issue on Slot Antennas and Arrays, Electromagnetics, vol. 18, 1998 (to be published).

[ 113$]$ L. Josefsson, "Slot coupling and scattering," in IEEE Int. Antennas Propagat. Symp. Dig., Dallas, TX, pp., 942-945, I990.

[114] G.-X. Fan and J.-M. Jin, "Scattering from a cylindrically conformal slotted waveguide array antenna," IEEE Trans. Antennas Propagat., vol. 45 , no. 7 , pp. 1150-1159, July 1997.

[115] G.-X. Fan and J.-M. Jin, "Scattering from a large planar slotted waveguide array antenna," Special Issue on Slot Antennas and Arrays, Electromagnetics, vol. 18, 1998 (to be published).

[116] A. J. Sangster, "Polarisation diversity technique for slottedwaveguide array antennas." Mikrowellen Magazine, vol. 15, no. 3, pp. 237-243, June 1989.

[117] A. J. Sangster, H. Wang, P. Smith, and R. Jacobs, "Moment method solutions for polarization agile slots in bifurcated waveguide," Special Issue on Slot Antennas and Arrays, Electromagnetics, vol. 18,1998 (this issue).

[118] K. Solbach, "Some millimeter-wave slotted array antennas", $14^{\text {th }}$ European Microwave Conference (EuMC), Liège, pp 181-186, 
1984.

[1 19 ] L. Sikora and J. Womack, "The art and science of manufacturing waveguide slot-array antennas", Microwave Journal, vol. 31, pp 157-162, June 1988.

[120] S. Brunzell and $H$. Magnusson, "Lightweight CFRP waveguide array”, Military Microwaves '84 Conference, 1984.

[121] D. Jönsson, "Metallisation methods \& applications", Proc. ESA Symp. Space applications of advanced structural materials, ESTEC, Noordwijk (NL), 21-23 March, 1990.

[122] J. Cross, D. Collier, and L. Goldstone, "Multimode performance from a single slotted array antenna”, Proc. JINA Conf., pp 397-400, 12-14 Nov., 1992.

[123] E. Brookner, "Aspects of modern radar", Lex Book, Lexington, MA, 1996.

[124] R. E. Cowdery and W.A. Skillman, "Development of the airborne warning and control system (AWACS) radar", IEEE Trans. Aerospace Electr. Syst., vol. 31, no. 4, pp 1357-1365, Oct. 1995.

[125] D. A. Ethington, "The AN/TPQ-36 and AN/TPQ-37 Firefinder radar systems", EASCON-77 Conf. Rec., pp 4-3A to 4-3F, 1977.

[126] I. Karlsson, "Applications of waveguide arrays in commercial and military radars", Antenna Applications Symp., Allerton House, Ill., 1994.

[127] A. G. Derneryd and T. C. Lorentzon, "Design of a phase/frequency scanned array antenna with non-resonant slotted ridge waveguide elements", IEEE AP-S Int. Symp., London, Ont., Canada, pp 17281731, 1991.

[128] H. Shnitkin, "A unique Joint Stars phased -array antenna", Microwave Journal, vol. 34, pp 131-141, Jan. 1991.

[129] L. Josefsson, A. Derneryd, and R. Lagerlöf, "Electronic scanning with slotted waveguide arrays", Radarcon 90, Adelaide, Australia, 18-20 April 1990.

[130] R. Lagerlöf and L. Josefsson, "A phase scanned AEW radar antenna”, IEEE AP-S Int. Symp., Dallas, 7-10 May, 1990. 